\title{
GIS-Based Method for Estimating Surficial Groundwater Levels in Coastal Virginia Using Limited Information
}

\author{
R. D. Johnson ${ }^{1}$; D. J. Sample, M.ASCE ${ }^{2}$; and K. J. McCoy ${ }^{3}$
}

\begin{abstract}
In many coastal areas, high water tables are present, complicating installation of some stormwater best management practices (BMPs) that rely on infiltration. Regional estimates of the seasonal high water table (SHWT) often rely on sources such as soil surveys taken over a decade ago; these data are static and do not account for groundwater withdrawals or other anthropogenic impacts. To improve estimates of the SHWT, we developed a GIS-based methodology relying on surface water elevations. Data sources included a $1.5-\mathrm{m}(5.0 \mathrm{ft})$ resolution Lidar-derived digital elevation model (DEM), aerial imagery, and publicly available shapefiles of water boundaries. Twenty-six groundwater monitoring wells were screened to eliminate well locations influenced by pumping, yielding 22 wells. In coastal Virginia, tidal water bodies and ditches form terminal boundaries for discharge from the water-table aquifers and permit water table elevations to be fixed at the landward boundaries of surface water bodies. Water table elevations interpolated from well data and boundary elevations were used to create a triangulated irregular network representing the water table elevations for November 2012, which was the date of the DEM. An adjustment factor, calculated from the highest recorded April water table depth from long-term groundwater monitoring data, was added to estimate the SHWT elevation. SHWT elevations were subtracted from the DEM to yield SHWT depth, which was compared with long-term monitoring well data, yielding an $R^{2}$ value of 0.91 . Residual errors were random, although the method underpredicted the highest expected SHWT and overpredicted the median SHWT. The SHWT depth map was validated by using water table depths from 57 soil borings at 10 different sites, and consistently matched observations better than available soil survey estimates. The SHWT depth map could be useful for BMP siting and feasibility studies in similar hydrogeological settings. DOI: 10.1061/(ASCE)IR.1943-4774.0001313. @ 2018 American Society of Civil Engineers.
\end{abstract}

Author keywords: Groundwater; Seasonal high water table; Geographic information system (GIS); Coastal geomorphology; Low-impact development (LID); Digital elevation model (DEM).

\section{Introduction}

Water table depth is a critical design consideration in many environmental projects, such as infiltrative stormwater best management practices (BMPs). These types of BMPs are becoming more needed for low-impact development (LID), a development strategy that seeks to replicate predevelopment hydrology. One example of these LID practices is bioretention. In Virginia (Virginia Department of Environmental Quality 2011), a minimum media depth of $0.6 \mathrm{~m}$ is required, and in coastal Virginia, underdrains are normally needed to compensate for subsoils with low infiltration capacity. Bioretention meets runoff volume reduction goals more often, and has improved pollutant removal when the filtration media is deeper, such as at $0.9 \mathrm{~m}$ (Brown and Hunt 2011). However, bioretention units may not be viable in locations with shallow groundwater. Intersection with the water table can increase discharge of pollutant loads and may cause negative impacts by

${ }^{1}$ Graduate Student, Dept. of Biological System Engineering, Virginia Polytechnic Institute and State Univ., Blacksburg, VA 24061. Email: rdjohnson@vt.edu

${ }^{2}$ Associate Professor, Hampton Roads Agricultural Research and Extension Center, Virginia Polytechnic and State Univ., Virginia Beach, VA, 23455 (corresponding author). Email: dsample@vt.edu

${ }^{3}$ Hydrologist, Virginia-West Virginia Water Science Center, US Geological Survey, 1730 E Parham Rd., Richmond, VA 23228. Email: kjmccoy@usgs.gov

Note. This manuscript was submitted on March 20, 2017; approved on January 5, 2018; published online on April 27, 2018. Discussion period open until September 27, 2018; separate discussions must be submitted for individual papers. This paper is part of the Journal of Irrigation and Drainage Engineering, (C) ASCE, ISSN 0733-9437. draining groundwater through the underdrain and altering the groundwater flow regime (Brown and Hunt 2012). Furthermore, water table proximity limits infiltrative capacity, and thus the performance of BMPs (Susilo et al. 2009). Achieving stormwater volume and quality goals through BMP application is only possible if BMPs are designed and installed with adequate separation from the water table.

Recently, several states, including Virginia, have mandated implementation of LID. Virginia stormwater regulations use the runoff reduction method (RRM) to estimate postconstruction runoff volume and nutrient loads from sites (Battiata et al. 2010); the RRM encourages the use of infiltration-based BMPs. The RRM assumes compliance with BMP design specifications, which are applied uniformly across Virginia, irrespective of physiographic region (Virginia Department of Environmental Quality 2013a). The coastal plain region of Virginia is characterized by flat terrain, shallow water tables, and soils with low permeability that limit the application of infiltration-based BMPs (Virginia Department of Environmental Quality 2013b). The most limiting physical constraint in coastal Virginia, when locating, selecting, and designing individual BMPs, is the depth to water table in shallow unconfined settings. Thus, a method to estimate the seasonal high water table (SHWT) depth is critical to narrowing the choice of BMPs in coastal locations

Direct SHWT measurements are often only sparsely available, are resource intensive to collect, and may be unreliable (Sander et al. 1996). Redoximorphic features (RMFs) of the soil, such as low chroma colors, can be used as a SHWT indicator (Vepraskas and Wilding 1983). Morgan and Stolt (2006) found that the SHWT was often above horizons with common RMFs, and sometimes 
present in horizons with no RMFs. The authors also determined that soil texture should be considered when making SHWT interpretations based on RMFs. Humphrey and O'Driscoll (2011) corroborated this finding, and found that low chroma colors were better predictors of SHWT depth when SHWT depths were relatively shallow. Overall, RMFs are a good starting point for making SHWT predictions, particularly in loamy soils (Morgan and Stolt 2006). Coarse soils and soils with deep water tables require more consideration for estimating the SHWT.

GIS have been used to bridge the gap between soil RMFs and physical water table measurements with respect to groundwater features. Multicriteria decision analysis (MCDA) based on remote sensing (RS) and GIS information has been applied extensively for the delineation of potential areas of groundwater development and recharge zones (Agarwal and Garg 2016; Kumar et al. 2014; Machiwal et al. 2011; Madani and Niyazi 2015; Patil and Mohite 2014; Sahoo et al. 2015). The MCDA technique involves overlaying thematic layers of features that contribute to favorable conditions for groundwater development, such as slope, soil, topography, and rainfall. Each thematic layer is assigned a weight that determines influence when the thematic layers are combined into a single groundwater potential map, which reports a qualitative measure of groundwater potential. This technique is associated with greater success when more thematic layers are used to generate the groundwater potential map (Kumar et al. 2014). Similar multivariate techniques have been used to assess factors controlling the distribution of groundwater recharge, a controlling factor on water table morphology, in other areas of Virginia (Sanford et al. 2015).

Few published studies are available that used GIS and RS technologies to quantitatively estimate groundwater levels with limited information, short of a hydrogeologic modeling study. Vijay et al. (2011) used kriging to interpolate the water table surface from water elevations measured at 35 production wells north of the Bay of Bengal in India and used it to characterize seasonal water table fluctuations. Direct interpolation of water table measurements is ideal when data are sufficiently dense, but indirect methods must be used when monitoring data are sparse. The D.C. Water Resources Research Center (1995) used elevation points of surface water bodies, groundwater monitoring well data, and soil boring data to generate water table contours via kriging. Li et al. (2017) developed a similar method by using quantile regression. McKenzie et al. (2010) inferred water table levels from surface water elevations when actual measurements were not available. When water level measurements were too sparse to effectively construct a water table surface, Peck and Payne (2003) used USGS monitoring data to create a linear regression model that predicted the water table elevation on the basis of land surface elevation. They applied the linear regression function spatially using GIS and set surface water elevations as boundary points. These indirect studies investigated an average water table condition. There is a need for a method to assist in estimating the SHWT, rather than using an average condition, with readily accessible spatial data for improving BMP siting and design.

The objective of this study was to develop a GIS-based methodology for estimating the SHWT elevation in a coastal setting of the Mid-Atlantic using limited information gathered from readily accessible GIS data. The resulting data can be used within the study area to help planners identify where infiltration-based BMPs are feasible. A BMP planning tool was recently developed by Johnson and Sample (2017) using results of the GIS-based SHWT method, described herein as input. The GIS-based SHWT method can be used in similar hydrogeologic settings for BMP planning outside of the study area.
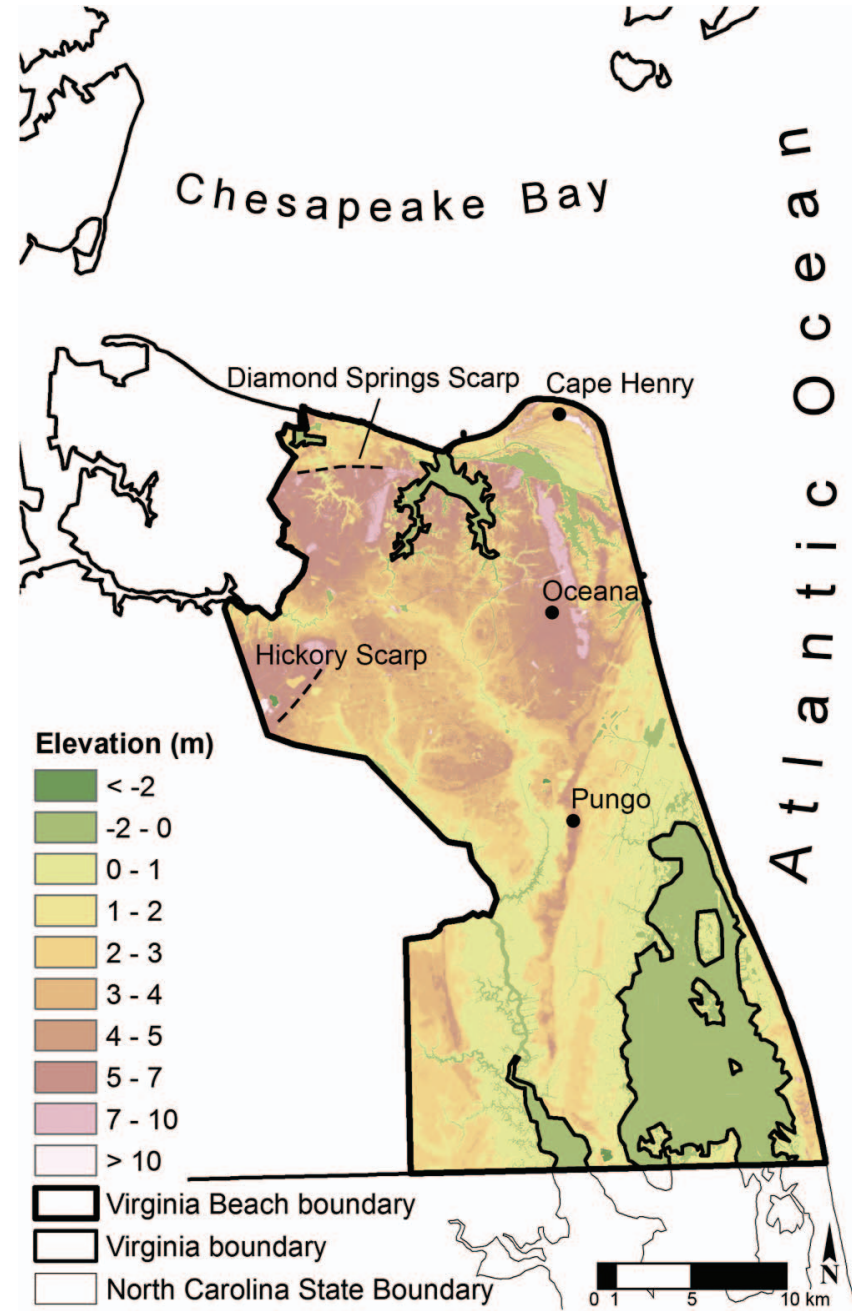

Fig. 1. (Color) Virginia Beach study area including elevation, relative location, and prominent geographic features.

\section{Study Area}

The city of Virginia Beach is located in southeastern Virginia adjacent to the Atlantic Ocean and the Chesapeake Bay, as noted in Fig. 1, and encompasses $808 \mathrm{~km}^{2}$ of coastal lowlands and wetlands. The barrier beach after which the city is named stretches about $56 \mathrm{~km}$ from Cape Henry at the entrance of Chesapeake Bay southward to the North Carolina border. The topography of Virginia Beach is dominated by the north-south trending depositional morphology of ancient barrier-and-lagoonal environments (Oaks and Coch 1973). Ancient barrier complexes form locally high northward trending ridges at Oceana and Pungo that rise to elevations 6.1-7.6 $\mathrm{m}$ above sea level. Sand dunes along the present coastline rising more than $24.4 \mathrm{~m}$ above sea level are visible at Fort Story near Cape Henry, Virginia. Topographic relief of Virginia Beach is, however, generally low and flat, and the area has an average altitude of $3.7 \mathrm{~m}$ above sea level.

The water table fluctuates in response to precipitation, evapotranspiration, and anthropogenic activities at various temporal scales (James and Fenton 1993). In Virginia Beach, long-term records of groundwater levels show that the SHWT occurs in early spring, with water level typically declining through summer because evapotranspiration and use of the aquifer for irrigation increases (Smith 2003). Seasonal pumping of confined or semiconfined aquifers at depths greater than $18.3 \mathrm{~m}$ can result in decline of 
groundwater levels by as much as $7.6 \mathrm{~m}$ below sea level during summer months in Virginia Beach (Eggleston 2010). Few measurements are available to assess the influence of pumping or climate on shallower flow systems $(<9.0 \mathrm{~m}$ depth) making spatial extrapolation of observed SHWT depths difficult.

\section{Methods}

\section{Long-Term Monitoring Data}

The USGS monitors groundwater levels in the surficial aquifer at shallow well locations in Virginia Beach. The shallow aquifer is generally considered unconfined and representative of the water table (Smith and Harlow 2002). Wells in the active groundwater network with a top of screen less than $21.3 \mathrm{~m}$ (70 ft) below the land surface were considered for use as comparison points. When wells were located within $150 \mathrm{~m}$ of another well, the shallower well was used. Wells were eliminated from use when data from October 2010 or November 2012 was unavailable, or if the data suggested the well was significantly influenced by localized pumping. Twenty-two wells were chosen as representatives of the water table and were used in further analyses. The well locations can be seen in Fig. 2, along with the surface elevation of the area. The wells were identified using a simple integer code, which is decoded in Table 1 with the site number, station name, and topof-screen depth.

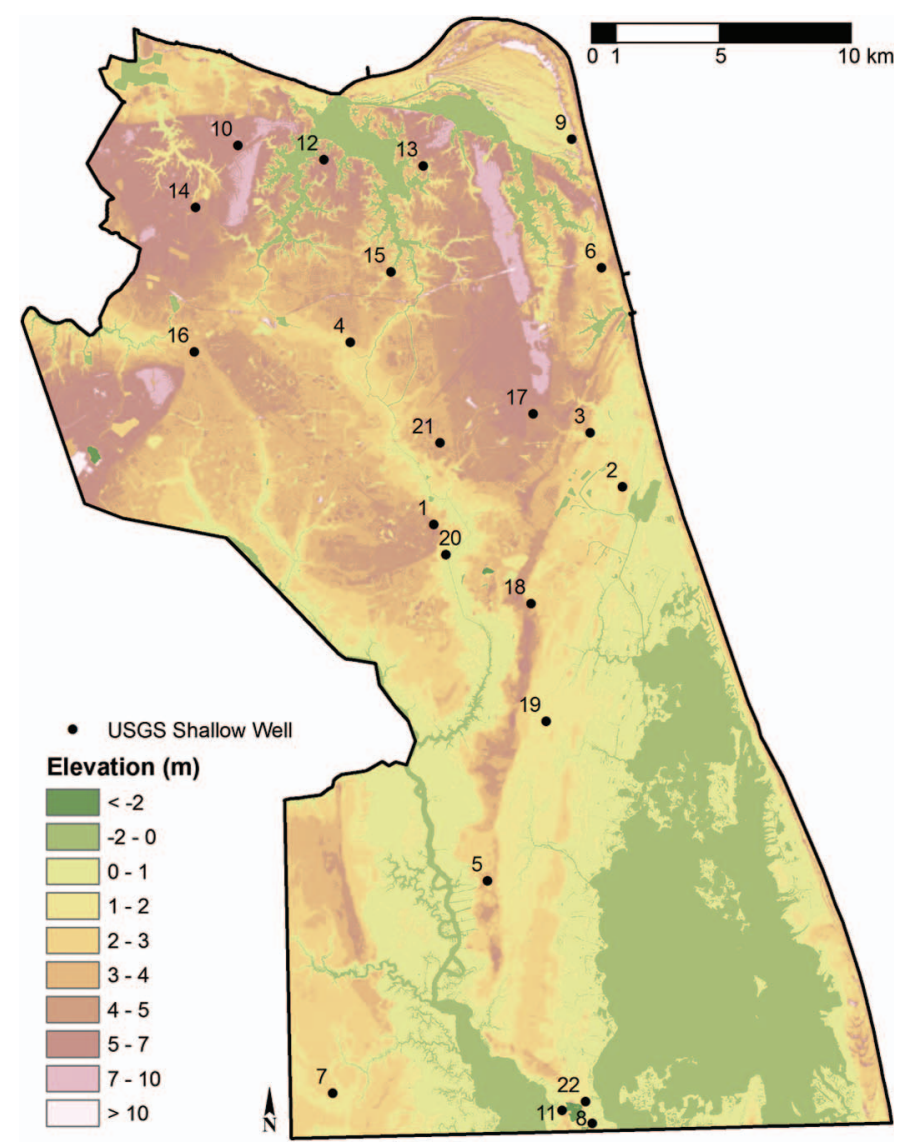

Fig. 2. (Color) Locations of the active USGS shallow groundwater wells in Virginia Beach, Virginia. The wells are spread across the city and occupy a wide range of surface elevations. Refer to Table 1 for additional information about the wells.

\section{Available Soil and Hydrography Data}

The most readily available depth to water table information is accessed from the widely used Soil Survey Geographic (SSURGO) database. In 2011, SHWT depth was one of the most queried soil properties from the USDA Natural Resources Conservation Service Web Soil Survey (NRCS WSS), second only to hydrologic soil group (HSG) (Thompson et al. 2012). The SHWT information in the soil survey database is typically based on RMFs; however, it is recommended that local water table monitoring be used to calibrate the data (USDA NRCS 2015). No procedures for calibrating the data were presented. Because many hydrologic models are designed to read SSURGO data with minimal processing (Thompson et al. 2012), it can be assumed that calibration of the data seldom occurs.

The USGS shallow wells were used to examine the reliability of SHWT predictions from the soil survey. Virginia Beach SSURGO data were obtained from the USDA NRCS WSS. The soil type at each USGS shallow well was identified and the SHWT range for that soil type was compared to the observed values at each well. In some cases, the wells were located in soils that do not have an associated SHWT depth, such as the heavily disturbed Udorthent or Urban soil types. In these cases, the nearest soil type with a SHWT range was substituted at the well. The median of the SHWT range obtained from SSURGO were compared to the highest recorded April median at all 22 USGS shallow wells. A linear regression was performed to characterize the ability of SSURGO data to be used to predict the observed values. Residuals were inspected for patterns.

\section{Indirect Lidar-Based Interpolation}

An indirect method of estimating the SHWT was formulated on the basis of available spatial layers, including a digital elevation model (DEM), water surface shapefiles, and aerial imagery. The $1.5-\mathrm{m}(5.0 \mathrm{ft})$ resolution DEM was derived from Lidar data

Table 1. Twenty-two wells selected for analysis on the basis of top-ofscreen depth, available data, and proximity to other wells

\begin{tabular}{lccc}
\hline $\begin{array}{l}\text { Map } \\
\text { integer }\end{array}$ & USGS site identifier & USGS station name & $\begin{array}{c}\text { Top of screen } \\
\text { (m BLS) }\end{array}$ \\
\hline 1 & 364529076031501 & 62C 8 SOW 127 & 15.2 \\
2 & 364613075583202 & 63C 3 SOW 100C & 9.1 \\
3 & 364721075591701 & 63C 19 & 7.6 \\
4 & 364909076051101 & 62C 34 & 18.3 \\
5 & 363812076021202 & 62B 16 SOW 208B & 19.8 \\
6 & 365045075585301 & 63C 20 & 11.9 \\
7 & 363537076061002 & 62A 3 SOW 097B & 6.1 \\
8 & 363310075594002 & 63A 4 & 15.2 \\
9 & 365324075593202 & 62D 27 & 15.8 \\
10 & 365327076080501 & 61D 6 SOW 124 & 7.6 \\
11 & 363325076005201 & 62A 5 & 17.7 \\
12 & 365307076055302 & 62D 25 & 18.3 \\
13 & 365256076032002 & 62D 23 & 19.8 \\
14 & 365212076091202 & 61C 46 SOW 212B & 18.9 \\
15 & 365046076041602 & 62C 33 SOW 211B & 21.3 \\
16 & 364920076093202 & 61C 28 SOW 174B & 19.8 \\
17 & 364745076004303 & 62C 11 SOW 172C & 6.1 \\
18 & 364352076005401 & 62B 9 & 15.8 \\
19 & 364126076003501 & 62B 1 SOW 098A & 6.1 \\
20 & 364504076031301 & 62C 5 SOW 093 & 18.3 \\
21 & 364715076030801 & 62C 3 SOW 092B & 16.2 \\
22 & 363337075595002 & 63A 2 & 5.2 \\
\hline
\end{tabular}

Note: Refer to Fig. 1 for well locations. Top of screen is a depth given in meters below the land surface.

${ }^{a}$ Value represents well depth because top-of-screen depth was unavailable. 


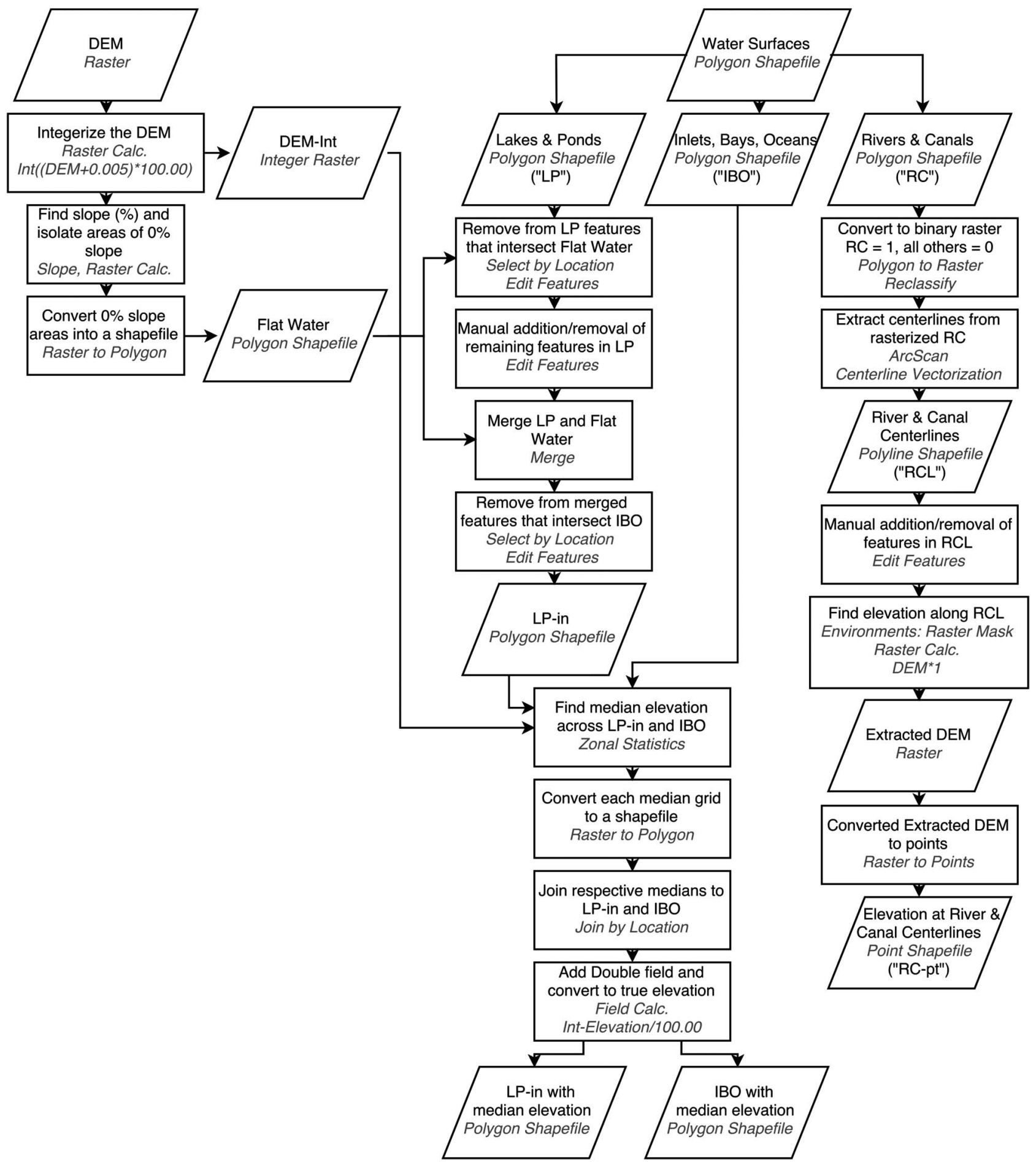

Fig. 3. Creation and conditioning of the shapefile input layers used to estimate the SHWT depth.

by Pictometry International Quality control investigations by the City of Virginia Beach showed that the DEM was accurate within $15 \mathrm{~cm}(0.5 \mathrm{ft})$ (C. Meyer, City of Virginia Beach Center for Geospatial Information Services, personal communication, 2015). Lidar data were collected in November 2012, and aerial imagery in April 2013.

A shapefile containing water surface features was obtained from the City of Virginia Beach's Open GIS website (Virginia Beach City GIS 2014). The shapefile was split into three separate shapefiles according to water surface type: lakes and ponds (LP); inlets, bays, and oceans (IBO); and rivers and canals (RC). These water features were inspected for accuracy and agreeance with the DEM and aerial imagery using a combination of manual inspection and GIS operations, described in the "Extracting Open Water Surface Elevations" section. The water surfaces and their associated elevations were used to create a triangulated irregular network (TIN), which was converted to a raster. An adjustment factor based on data from the USGS shallow monitoring wells was added to the raster and the result was subtracted from the DEM to yield SHWT depth. All GIS work was conducted using ArcGIS 10.3 (ESRI 2016). Figs. 3 and 4 illustrate the methodology used and provide insight into the specific ArcGIS operations that were conducted. 


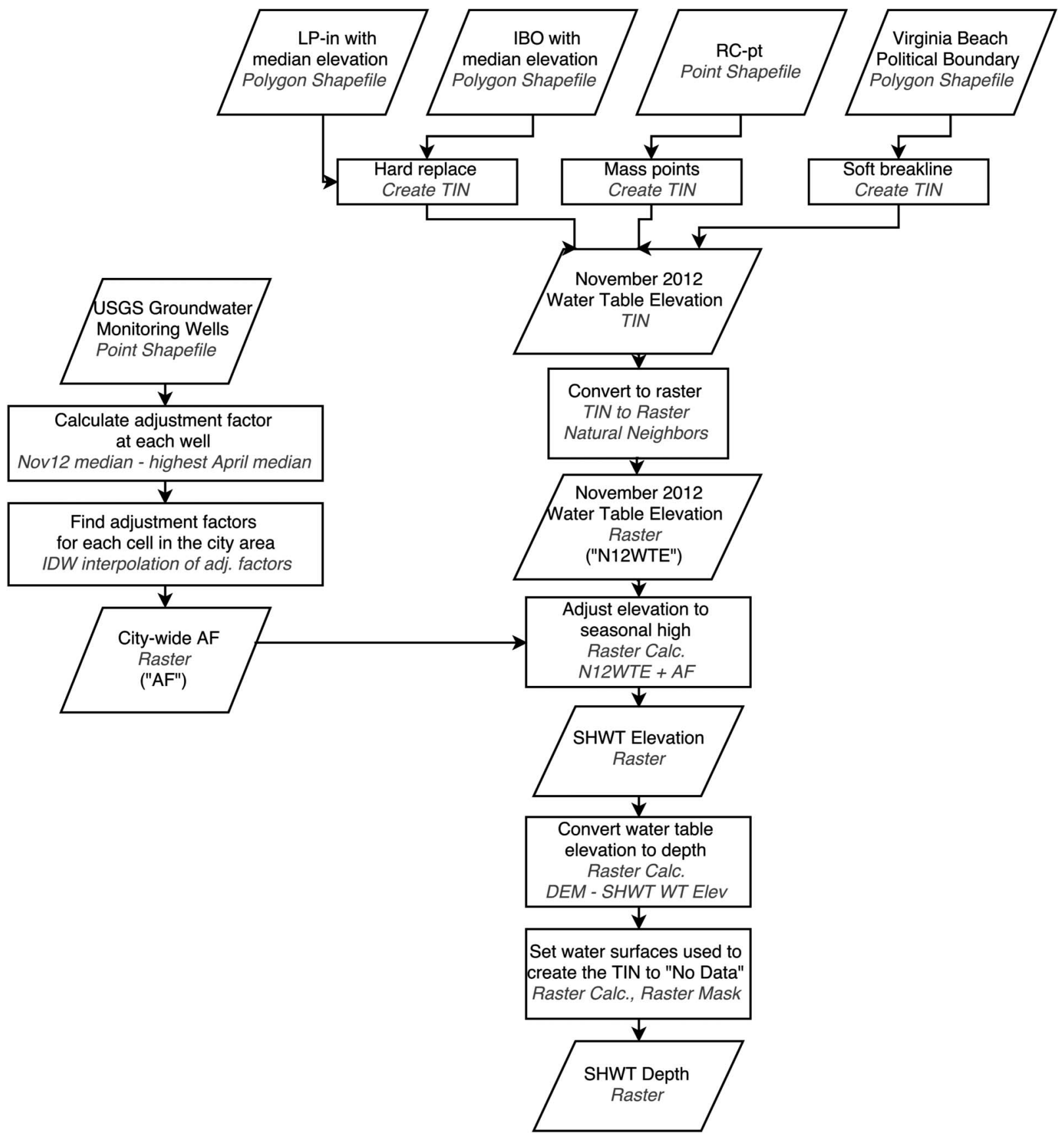

Fig. 4. Use of the shapefile input layers to generate the SHWT depth grid.

\section{Extracting Open Water Surface Elevations}

Visual evaluation of the lakes and ponds shapefile revealed that many ponds were misidentified. While it is possible that a pond previously existed in that location, or was planned for that location, the DEM and aerial imagery did not show a pond in that location. LP was in need of manual verification and editing to reduce the likelihood of false input data. Evaluation of the DEM indicated that flat areas, i.e., areas of $0 \%$ slope, only occurred at inland or closed water surfaces, thus areas with a slope of $0 \%$ verified the presence of an inland or closed water body at the time the DEM was created. These areas with $0 \%$ slope were matched with features in LP, and the matching features were not included in manual verification. Only lake and pond features with variation across their surface remained in LP for manual verification. Features were added and removed from LP on the basis of indicators in the DEM and aerial imagery, such as presence of a depression in the DEM and noticeable water in the aerial photo. Features with a surface area less than 0.04 ha $(0.1$ acre $)$ were removed. Once lake and pond locations were verified, the locations of $0 \%$ slope were added back to the LP shapefile. The median elevation across each feature was calculated and added to LP. LP was included in creation of the TIN with elevation at all points inside the polygon set to the same value, to model a level surface. This approach is consistent with the representation of surface water bodies as constant heads in previous groundwater flow simulations (Smith 2003)

A similar process was used for determining elevation of the shapes in the inlets, bays, and oceans shapefile. All but two features had a median elevation of $0.0 \mathrm{~m}$, or mean sea level. Those two 
features were small and had median elevations of less than $0.3 \mathrm{~m}$. IBO was also used in TIN creation with elevation at all points inside the polygon set to the same value, to model a level surface.

Rivers and canals do not have a static elevation across the water surface, so the median elevation method used on LP and IBO was not viable for assigning elevation to the features in the rivers and canals shapefile. To capture the water surface elevation change along the channel, RC ultimately needed to exist as a series of points rather than polygons or polylines. Stream centerlines were found unlikely to intersect the bank and give an erroneous water surface elevation.

ArcScan was used to generate centerlines from the RC shapefile using a process known as centerline vectorization, in which a polyline centerline is generated from contiguous sections of a binary raster. The resulting polyline file was manually checked for accuracy and edited. Features were added on the basis of proximity to other features or altered on the basis of intersection with bridges or the channel bank. Many features that were short and adjacent to an estuary were removed entirely, because those features did not represent a meaningful water surface. The edited polyline file was used as a raster mask to extract elevations from the DEM at the location of the polyline. Those elevations were converted to a point shapefile, and were then incorporated into the TIN.

In addition to the RC elevation points, and the LP and IBO elevation polygons, the political boundary of the city was incorporated to ensure all portions of the city were included in the resulting TIN without affecting the surface shape. The TIN was an estimate of the Virginia Beach water table elevation in November 2012, which was the date of the DEM. Using natural neighbors' interpolation, the TIN values were converted to a raster with resolution matching the DEM, yielding a grid that represented the water table elevation in November 2012.

\section{Adjusting for the Seasonal High}

In November, the groundwater elevation has typically recovered from midyear pumping but is still not as high as expected during the seasonal high window from late winter to early spring. When geotechnical evaluation takes place outside of the seasonal high window, the groundwater elevation is often adjusted using USGS monitoring data to estimate the SHWT in that location (G. Johnson, City of Virginia Beach Public Works, personal communication, 2015). Similarly, seasonal high data from USGS shallow monitoring wells were used to adjust the November 2012 water table elevations to the seasonal high. Without an adjustment, the groundwater elevation grid created by the TIN would not have been consistent with the high groundwater condition used in LID planning and design. An adjustment factor was found for each USGS shallow well location and interpolated to create a grid of adjustment factors. To convert the November 2012 water table elevation grid to a grid that represented the SHWT elevation, the interpolated adjustment factor grid was added to the November 2012 water table elevation grid.

The availability of groundwater depth data was highly variable across all wells. April was the most sampled month during the seasonal high window for the eight wells with the least data. Of the remaining 14 wells, 5 had their highest recorded daily median in April. The other nine wells had the highest recorded daily median earlier in the season, typically in February or March. While April may not represent the highest depths at all well locations, depths are consistently high during this month for all wells. The available April data at each well were consolidated into median April values for each year during the period of record. These median values were used to describe the SHWT in further analyses.
Table 2. Values used to determine the adjustment factor at each of the USGS shallow monitoring wells

\begin{tabular}{lccc}
\hline Station name & $\begin{array}{c}\text { November 2012 } \\
\text { median (m BLS) }\end{array}$ & $\begin{array}{c}\text { Highest April } \\
\text { median (m BLS) }\end{array}$ & $\begin{array}{c}\text { AF } \\
(\mathrm{m} \mathrm{BLS})\end{array}$ \\
\hline 62C 8 SOW 127 & $2.99^{\mathrm{a}}$ & 1.91 & 1.09 \\
63C 3 SOW 100C & $1.62^{\mathrm{a}}$ & 1.16 & 0.46 \\
63C 19 & $1.66^{\mathrm{a}}$ & 1.08 & 0.58 \\
62C 34 & $1.96^{\mathrm{a}}$ & 1.31 & 0.65 \\
62B 16 SOW 208B & $2.94^{\mathrm{a}}$ & 2.51 & 0.43 \\
63C 20 & $2.33^{\mathrm{a}}$ & 1.79 & 0.53 \\
62A 3 SOW 097B & $0.33^{\mathrm{a}}$ & 0.10 & 0.23 \\
63A 4 & $2.07^{\mathrm{a}}$ & 1.80 & 0.27 \\
62D 27 & $0.91^{\mathrm{a}}$ & 0.71 & 0.19 \\
61D 6 SOW 124 & 2.21 & 1.17 & 1.03 \\
62A 5 & $4.56^{\mathrm{a}}$ & 2.81 & 1.76 \\
62D 25 & 5.26 & 5.16 & 0.10 \\
62D 23 & $4.50^{\mathrm{a}}$ & 3.74 & 0.77 \\
61C 46 SOW 212B & 3.81 & 3.25 & 0.56 \\
62C 33 SOW 211B & 2.78 & 2.58 & 0.20 \\
61C 28 SOW 174B & 2.41 & 1.83 & 0.58 \\
62C 11 SOW 172C & 1.98 & 1.65 & 0.34 \\
62B 9 & 1.31 & 1.26 & 0.05 \\
62B 1 SOW 098A & 0.57 & 0.31 & 0.26 \\
62C 5 SOW 093 & 1.36 & 0.92 & 0.44 \\
62C 3 SOW 092B & 2.24 & 1.47 & 0.78 \\
63A 2 & 1.08 & 0.90 & 0.18 \\
\hline
\end{tabular}

Note: The AF is the difference between the November 2012 median and the highest April median water level depths BLS recorded at each well.

${ }^{a}$ Used October 2012 median because November 2012 median was not recorded.

The adjustment factor for each USGS shallow well was based on the difference between the observed USGS median depth to the water table in November 2012 and the observed USGS highest April median water depth at each well. The highest April median was used because it yields the highest expected SHWT across the city, which is useful for conservative siting of BMPs. Additionally, use of the highest April median mitigates the effects of the interpolation method, which results in lower-than-expected water table elevations for reasons which are assessed in the "Discussion" section. The difference between the observed USGS November 2012 median well depth and the observed USGS highest April median well depth is noted as the adjustment factor (AF) in Table 2. At 11 of 22 wells, the observed USGS October 2012 median well depth was substituted for the observed USGS November 2012 median well depth due to lack of November 2012 data.

The AF was interpolated between the 22 wells using inverse distance weighted (IDW) interpolation with the default ArcGIS 10.3 settings, yielding an approximate adjustment factor for each cell in the city boundary. The interpolated AF grid was added to the November 2012 water table elevation grid, effectively raising the water table. The result was a water table elevation grid that had been adjusted to estimate the SHWT elevation. The SHWT depth model was created by subtracting the SHWT elevation from the DEM. The water surfaces used to generate the SHWT model were empty cells in the final map.

\section{Comparison to Flooding Data}

Areas of shallow groundwater $(<0.6 \mathrm{~m})$ were expected to have a high frequency of reported flooding during the seasonal high months. The Virginia Beach Department of Public Works Operations Management (2016) provided citizen-reported flooding data from October 2007 to March 2016. Flooding reports from 
January to April were counted and consolidated by location during the observations time period. The flooding frequency data were geocoded in ArcGIS 10.3 (Esri 2016) using address locators built from parcel and street information obtained from the City of Virginia Beach Open GIS Data website (City of Virginia Beach 2016). The geocoded points were then filtered; points were retained only if $100 \%$ of their associated flooding reports occurred between January and April. A total of 311 flood report points were used to create a point density map based on a $0.75-\mathrm{km}$ circular neighborhood radius. Areas with a density greater than two reports per square kilometer were visually examined for patterns.

\section{Statistical Analysis}

Simple statistical methods were applied on the results to assess trends and quantify errors. A box plot was used to assess and compare frequency of results. A simple linear regression was performed to test the relationship between the SHWT model and observed values, residual errors were assessed using root mean square (RMSE) and sum of squared residuals (SSR). A normal distribution plot was used to test normality, which is a requirement of linear regression.

\section{Results}

\section{Evaluation of SSURGO Water Table Estimates}

Investigation of SSURGO data for the city of Virginia Beach, Virginia, revealed that $82 \%$ of the land area was estimated to have a SHWT within $0.9 \mathrm{~m}$ of the land surface, and $64 \%$ of the land area was estimated to have a SHWT within $0.3 \mathrm{~m}$ of the land surface; $11 \%$ of the land area in Virginia Beach has no listed water table information. These results suggest that use of infiltration-based BMPs in Virginia Beach is tightly constrained by the SHWT because the SHWT is not adequately deep to allow appropriate BMP construction and performance.

Comparison of the highest observed April median depths to the median of the SSURGO-predicted range shows that the SSURGO values are a poor $\left(R^{2}=0.19\right)$ predictor of the actual SHWT depth at well locations. A simple linear regression was performed on the data (Fig. 5), and residuals (the difference between the observed USGS and predicted SSURGO values) are shown in Fig. 6. The residuals exhibit wide variability for the same predicted value and are concentrated above the $x$-axis, with a mean residual value of $1.4 \mathrm{~m}$ and a $1.7 \mathrm{~m}$ root mean square error. The observed SHWT depth was at least $0.9 \mathrm{~m}$ deeper than the SSURGO-predicted values at 15 of the 22 wells.

Statistical and visual inspection indicate that the SSURGO data overpredict SHWT elevations at well locations in Virginia Beach. This is in contrast to the literature, which suggested the SHWT is often higher than soil RMF indicators (Humphrey and O'Driscoll 2011; Morgan and Stolt 2006). A likely explanation for the difference is that the RMFs used to predict the SHWT depth are relict features formed before some process locally lowered the water table (Daniels et al. 1971). In many places, groundwater levels in Virginia Beach are lowered by pumping for irrigation or dewatering by drainage ditches, surface mines, and sand pits (Smith 2005). The USDA NRCS (2015) cautions that some conditions may alter the usual correspondence between soil morphology and hydrology and, in such cases, recommends calibrating the RMFs with monitoring data or the presence of reducing conditions. The SSURGO data were determined to be unreliable for predicting the SHWT in Virginia Beach, Virginia, because the data likely ignore drawdown effects.

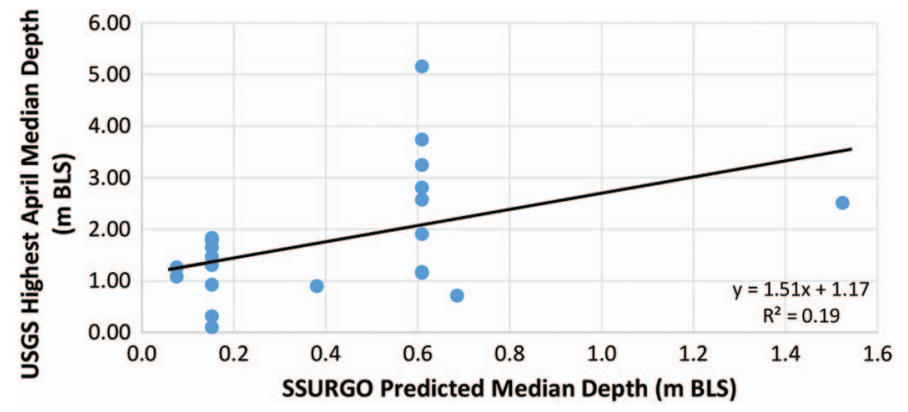

Fig. 5. (Color) Observed water depths at USGS wells versus predicted depths comparing the highest April median depths to the median SSURGO-predicted depths. The linear regression confirms that SSURGO is a poor predictor of actual SHWT depths in Virginia Beach, Virginia.

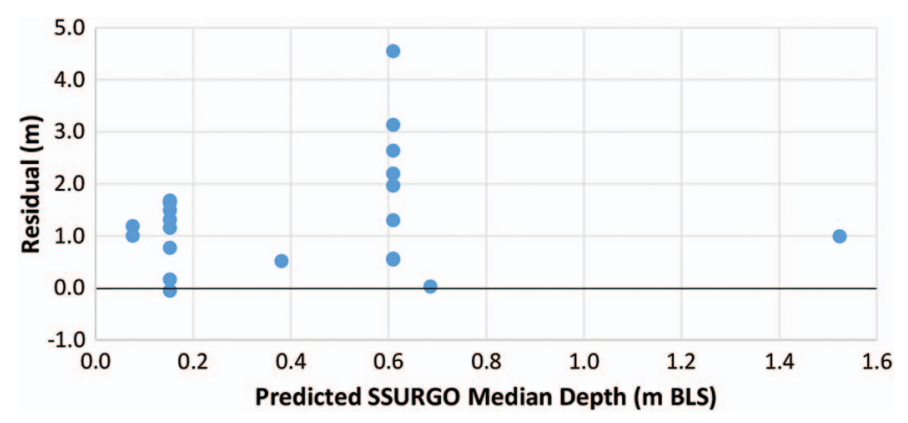

Fig. 6. (Color) Residual plot of the difference between the USGS shallow well observations and SSURGO predictions. SSURGO predicts the SHWT as much higher than observed.

\section{Visual Evaluation of the GIS-Based SHWT Model}

The final SHWT model can be seen in Fig. 7. The SHWT elevation grid can be seen in Fig. 8. The grid shows the expected pattern in water table depth across the city. Northern elevations are relatively high with surrounding water bodies at a relatively low elevation, which suggested a deeper SHWT. Wetlands dominate the southern watersheds and a SHWT near the surface is expected (Smith 2003). Water tables extending above the land surface $[<0 \mathrm{~m}$ below land surface (BLS)] are predicted in some portions of the developed city, particularly in street depressions.

In November 2012, Virginia Beach received lower-than-average rainfall-3.17 cm compared with the average $7.36 \mathrm{~cm}$-following Hurricane Sandy in October 2012 (Northeast Regional Climate Center 2015). The drier-than-normal conditions suggest that some water surface elevations were more representative of the water table because they were not storing much runoff. However, other water bodies could have been fuller than expected because the aquifers were slow to dewater after Hurricane Sandy and subsequent rain events. An understanding of water table response to precipitation events of varying intensity is not clear, but may account for the higher-than-expected SHWT prediction at some locations and not others.

The final flood report density map (Fig. 9) was used to evaluate the likelihood of predicted shallow water tables, including groundwater flooding of street depressions. Areas with report density greater than two per square kilometer were used to filter the SHWT model for visual inspection, shown in Fig. 10. Clusters of points not 


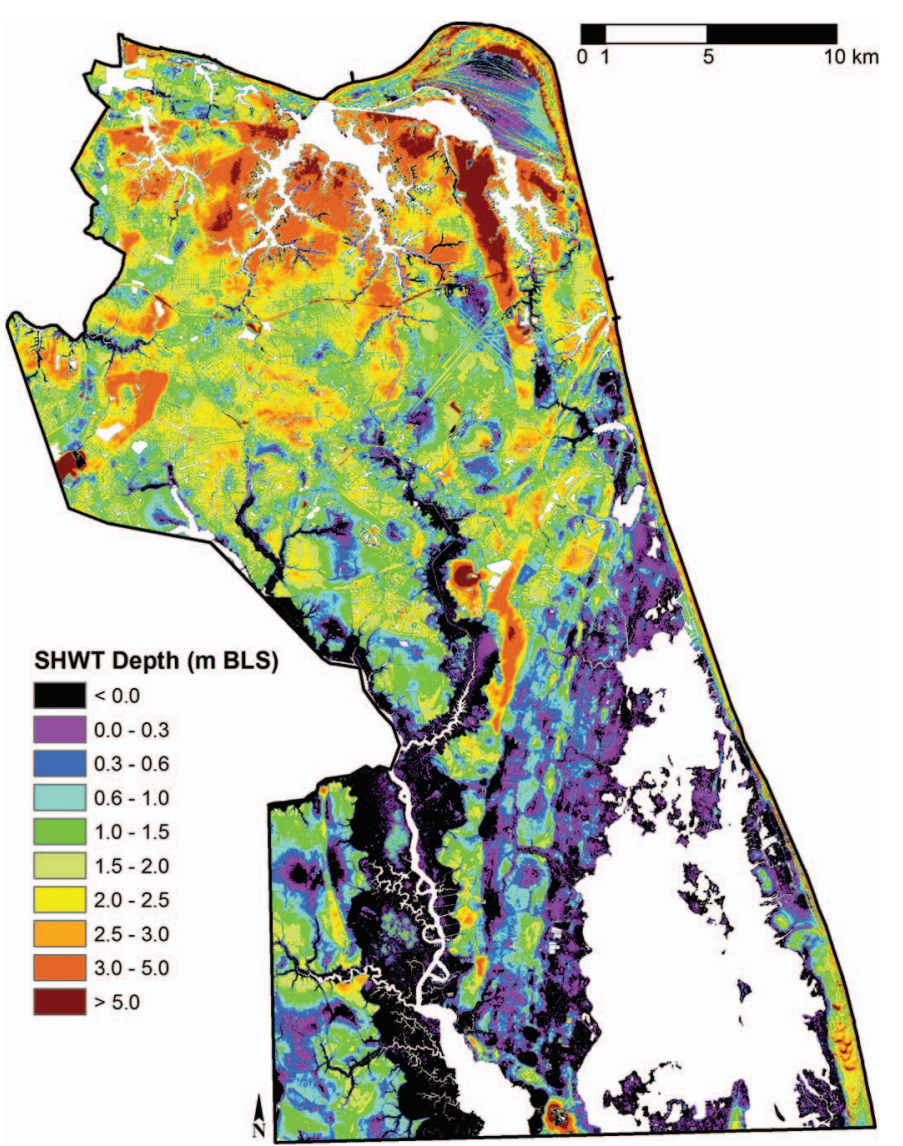

Fig. 7. (Color) Final SHWT depth grid in meters below the land surface (BLS). Depths of $<0 \mathrm{~m}$ BLS are locations where the SHWT may rise above the land surface elevation.

adjacent to tidal-influenced water bodies tended to have predicted depths less than $1.5 \mathrm{~m}$, with depths less than $0.6 \mathrm{~m}$ under street depressions. Three locations along the northern boundary adjacent to estuaries and the Chesapeake Bay showed similarly high SHWT predictions. The remaining clusters adjacent to tidal-influenced water bodies showed SHWT predictions greater than $1.5 \mathrm{~m}$. Because tidal-influenced water bodies had surface water elevations at mean sea level $(0 \mathrm{~m})$ in the DEM, these areas may underpredict the SHWT. However, they may also be prone to flooding owing simply to proximity of tidal-influenced waters. Similarly, areas not adjacent to tidal waters with SHWT predictions greater than $1.5 \mathrm{~m}$ tended to be in proximity to ponds.

Reports in the southern watersheds were very infrequent despite shallow SHWT predictions in those areas. Population density and development are much lower in the southern watersheds and were a likely explanation for low or no reporting. Two areas with predicted street depression springs in the northern, developed watersheds were not represented in the flood density map.

The flooding comparison was not expected to perfectly correlate with the shallow groundwater predictions. A number of factors beyond groundwater proximity influence flooding, including the storage capacity of nearby ponds, tidal influence, antecedent moisture, and storm size, among others. The flooding frequency map was based on citizens' reports and carried self-reporting biases, including influence from population density, lack of reports due to apathy or nonconcern, or false reports. Overall, the flooding frequency map provides some general insight via real-world correlations, at least for the developed area.

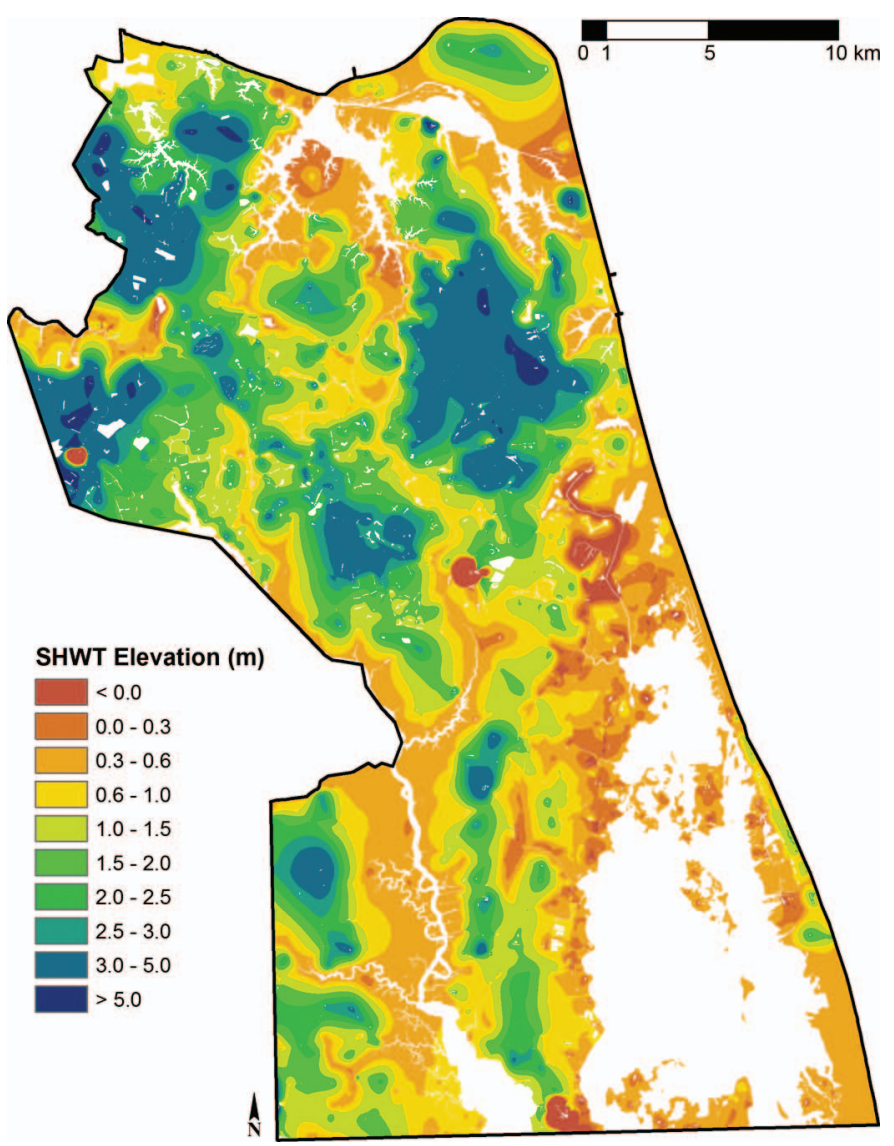

Fig. 8. (Color) Final SHWT elevation grid in m (NAVD 88 North American Vertical Datum).

\section{Comparison to Long-Term Monitoring Data}

The observed highest April median depths and the SHWT estimates were compared using linear regression [Fig. 11(a)] and residual analysis [Fig. 11(b)]. The observed values are the highest April median depths at each shallow USGS monitoring well, and the predicted values are the SHWT model value at each well location. The grid values are a strong predictor $\left(R^{2}=0.91\right)$ of the observed highest SHWT depths. The regression residual plot shows no obvious pattern but does indicate a slight negative bias, meaning the grid tends to predict the SHWT deeper than the highest observed values at the well locations. The negative bias occurs despite using the highest April median to calculate the adjustment factor. Underestimation of the highest expected water table is acceptable, because the highest recorded SHWT was not the most commonly observed SHWT depth.

The residuals were symbolized by magnitude and direction of divergence and displayed at the well locations in Fig. 12. The greatest magnitude residuals $(-0.67$ and $0.56 \mathrm{~m})$ both occurred in the northwest section of the city, but magnitudes were otherwise well dispersed. Positive residuals only occurred in the western half of the city, but negative residuals occurred throughout. Overall, there were no obvious and major spatial pattern in the residuals. The greatest magnitude residual was at the northernmost well, 61D 6 SOW 124, or Well 10, which is identified in Fig. 12. This well was farthest from any body of water used in the creation of the SHWT model, suggesting that the grid may not give reliable results in areas farther than $460 \mathrm{~m}$ from open water hydrogeological boundaries. Other high-magnitude residuals, however, occurred in close proximity to water surfaces. 


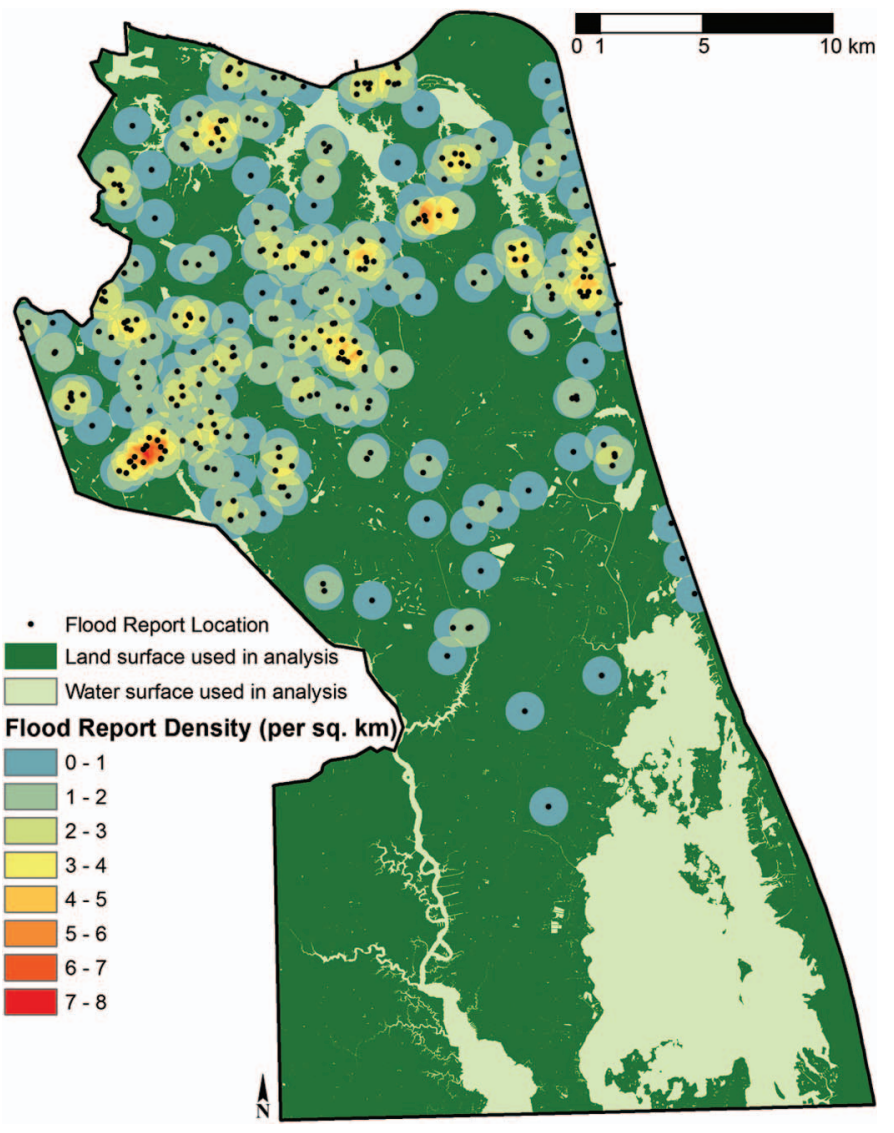

Fig. 9. (Color) Flood report density map generated from citizen reports of flooding between January and April for the years 2008 through 2016. Land and water surfaces used to create the SHWT depth grid are shown for convenience. Areas with zero reports are not shown.

Ideally, BMP siting analysis would use a conservative estimate of the SHWT-above the median expected SHWT but within the range of expected SHWT depth. The SHWT model value was plotted alongside a boxplot of the recorded April medians at each well in Fig. 13(a). Predictions at 10 wells meet the criteria for conservative BMP siting: above the median but within the range of data observed at the well. Predictions for six of the wells exceed the highest observed SHWT median, while two predictions fall below the lowest observed SHWT median. The remaining predictions are in the range of observed values at each well.

\section{Comparison of Predictions to the Median April Median}

Both the SSURGO and SHWT model values were compared with the median of observed medians at each well as a residual plot in Fig. 13(b) with descriptive statistics in Table 3. As before, the SSURGO residual was calculated using the difference between the USGS shallow well data and the median of SSURGO depth range at the well location. Residual comparison of the SHWT model and the SSURGO-predicted values demonstrates that the SHWT model provides a more realistic estimate across the city, even for average SHWT conditions. As expected, the SHWT model is consistently more reliable for estimating the SHWT depth. Both show positive bias, indicating that their predictions are higher than the observed median SHWT depth. The residual mean was $1.9 \mathrm{~m}$ for SSURGO and $0.3 \mathrm{~m}$ for the grid, indicating that the SSURGO data has a larger positive bias. The SSURGO data had a RMSE of $2.2 \mathrm{~m}$, while the SHWT model RMSE was $0.6 \mathrm{~m}$. From the RMSE

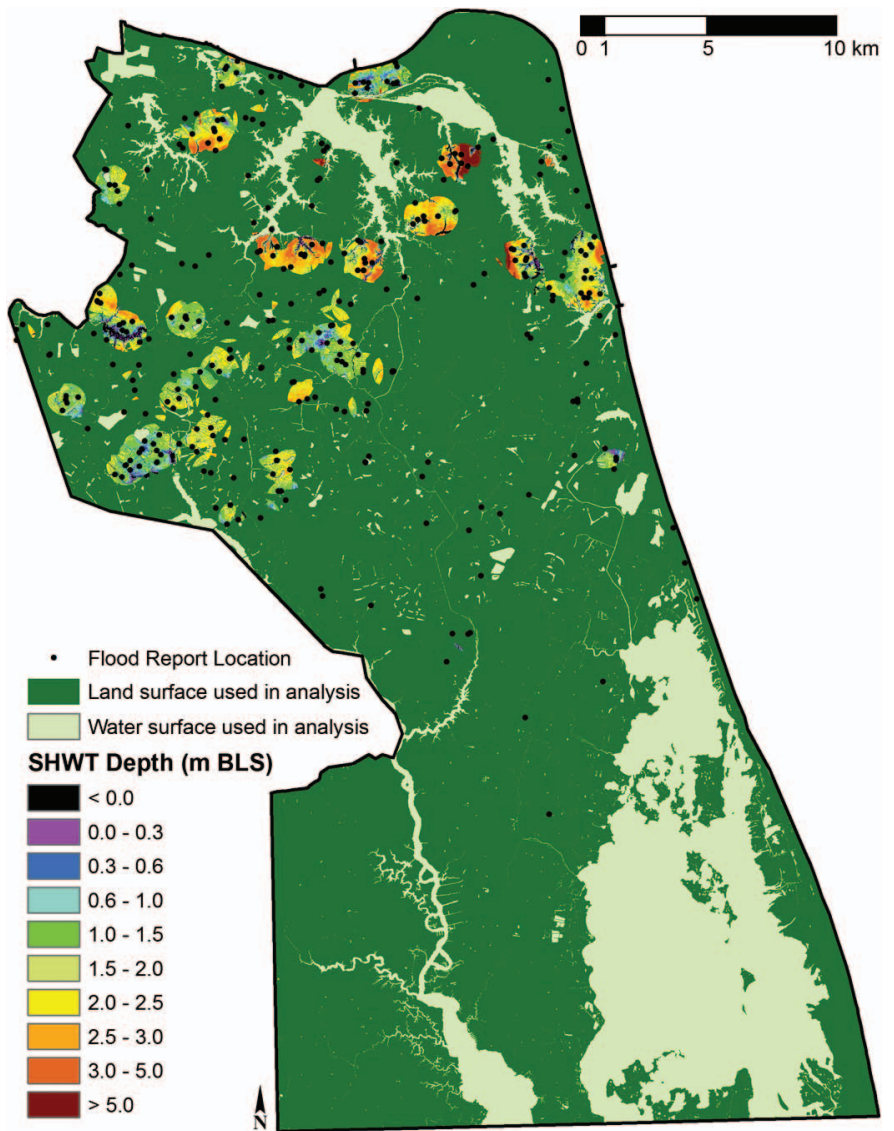

Fig. 10. (Color) SHWT depth grid filtered according to flood report density greater than 2 per $\mathrm{km}^{2}$ during the seasonal high window. $\mathrm{BLS}=$ Below land surface.

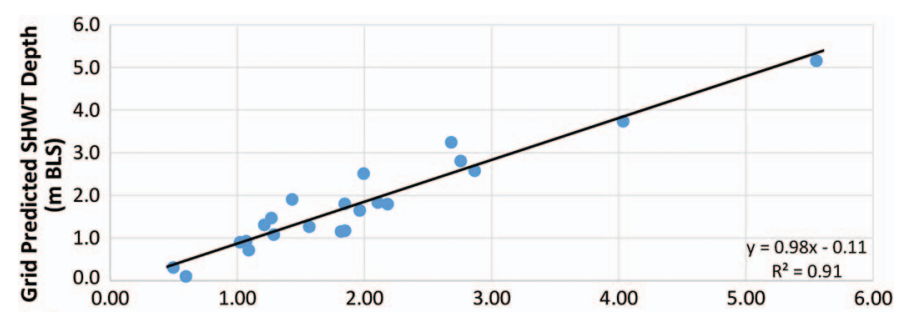

(a)

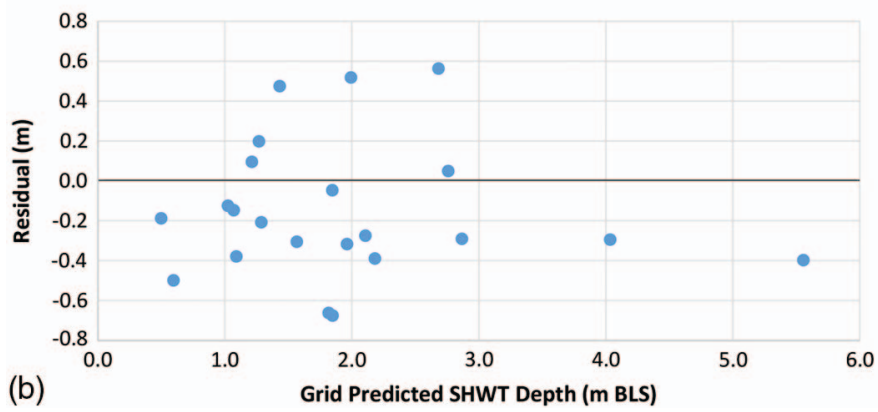

Fig. 11. (Color) (a) Linear regression of the USGS-observed highest April median water depths and the SHWT grid depth. The $R^{2}$ value is 0.91 ; the SHWT depth grid is a good predictor of the highest expected SHWT depths; and (b) the residual plot for the observed highest April median depths and the SHWT depth grid predictions. The residuals show no obvious pattern, but there is a slight negative bias. 


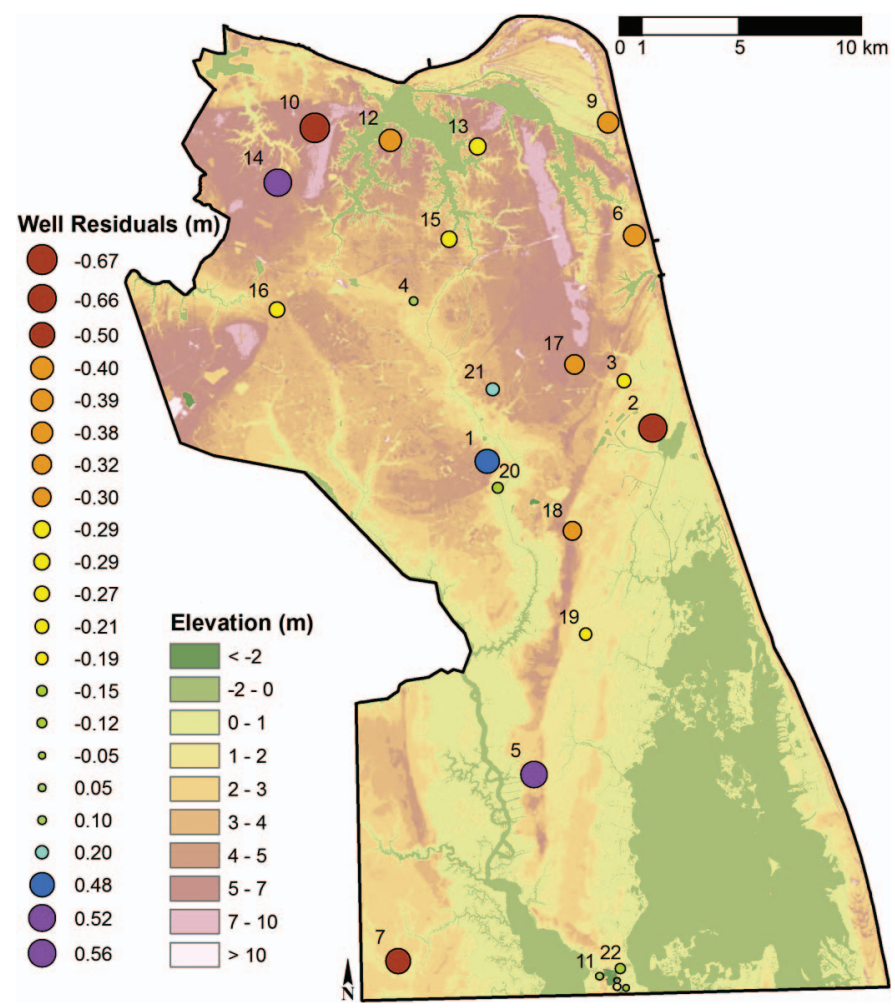

Fig. 12. (Color) Residuals symbolized by magnitude and sign at each USGS shallow monitoring well location. The greatest magnitude residuals in both directions occur in the northwest portion of the city. There is no obvious pattern or grouping of residuals.

comparison, the SHWT model is a much better predictor of the average expected SHWT depth at the well locations than SSURGO data.

\section{Comparison with Geotechnical Evaluation Data}

To validate the created SHWT model, geotechnical evaluations were obtained and digitized. Data availability was highly limited. Only evaluations occurring during the fall, winter, or spring months were considered because the high drawdown during summer months makes it difficult to reliably predict the seasonal high. There were 57 validation points available, representing data from 10 different sites located in the most developed sections of the city, shown in Fig. 14. Only one point was taken during the seasonal high. The remainder of the points were adjusted to the SHWT by the geotechnical evaluator; the final SHWT recommendations were used as validation points. The final recommendations are only an estimate of the actual SHWT depth, but were assumed to be the actual SHWT depth for the purposes of grid validation.

The validation point residuals are summarized with basic statistics in Table 4. Again, positive residuals mean that the grid estimates the SHWT to have a shallower surface than observed, while negative residuals indicate the grid estimates the SHWT to be deeper than observed. The residuals are plotted in Fig. 15(a), showing no obvious pattern and no positive or negative bias, supported by a mean residual near zero. Residuals were normally distributed [Fig. 15(b)]. The residual RMSE was $0.5 \mathrm{~m}$, thus the SHWT model was expected to be accurate within $0.9 \mathrm{~m}$ at a $95 \%$ confidence interval. Note that the accuracy relies on the assumption that the given seasonal high in the geotechnical evaluation reports was indicative of the expected SHWT at each location.

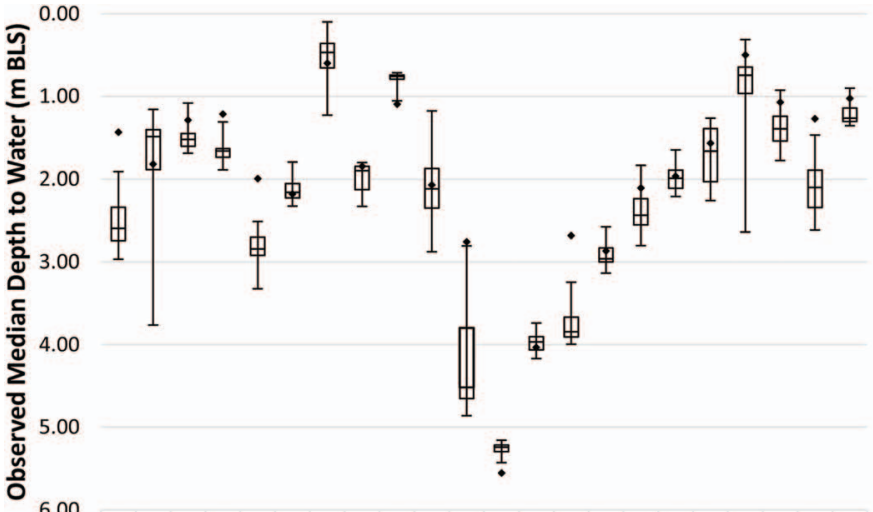

6.00

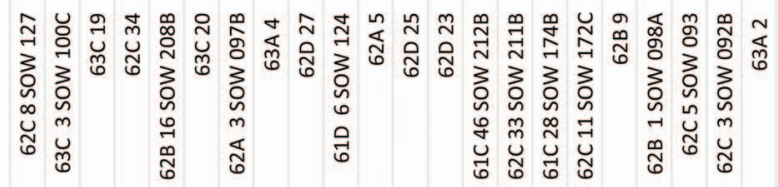

$\begin{array}{lllllllllllllllllllllll}1 & 2 & 3 & 4 & 5 & 6 & 7 & 8 & 9 & 10 & 11 & 12 & 13 & 14 & 15 & 16 & 17 & 18 & 19 & 20 & 21 & 22\end{array}$ USGS Well Station Name
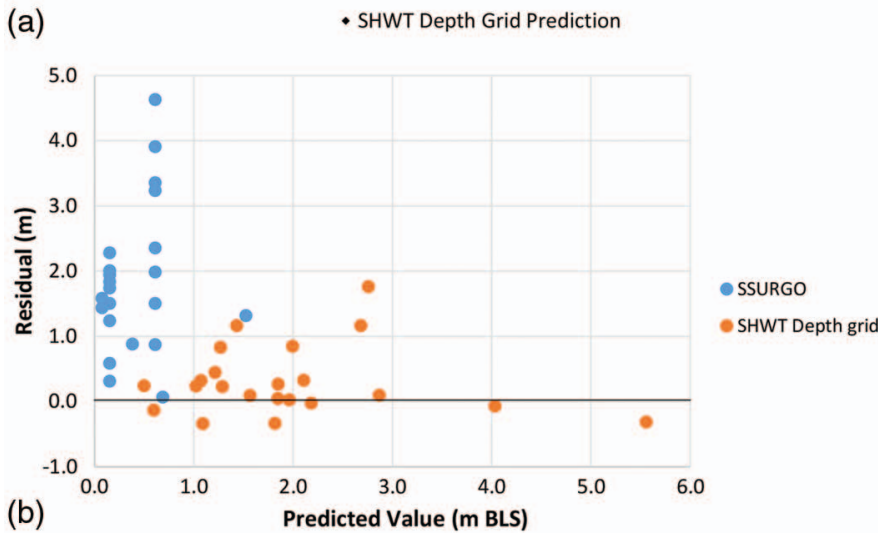

Fig. 13. (Color) (a) Comparison of the SHWT depth grid value to the overall range of April median data for each USGS shallow well; and (b) residual comparison of SSURGO and SHWT depth grid predictions to the median observed SHWT depth.

Table 3. Descriptive statistics comparing SSURGO and the SHWT model residual values

\begin{tabular}{lcc}
\hline Statistic & SSURGO & SHWT depth grid \\
\hline Residual mean $(\mathrm{m})$ & 1.9 & 0.3 \\
SSR $\left(\mathrm{m}^{2}\right)$ & 102 & 8.3 \\
RMSE $(\mathrm{m})$ & 2.2 & 0.6 \\
\hline
\end{tabular}

Although an accuracy of $\pm 0.9 \mathrm{~m}$ appears to be a wide margin of error, the error was reasonable considering the simplicity and pitfalls of the method, addressed in the "Discussion" section.

\section{Discussion}

Effective use of the SHWT model necessitates an understanding of the grid's limitations and sources of error. The source of greatest error is the simplification of complex hydrologic processes that determine water table elevation. The SHWT model was created from the elevations of water surfaces. The water surface elevations implicitly include past rainfall, evapotranspiration, and anthropogenic impacts at the time the Lidar was taken, although any effects 


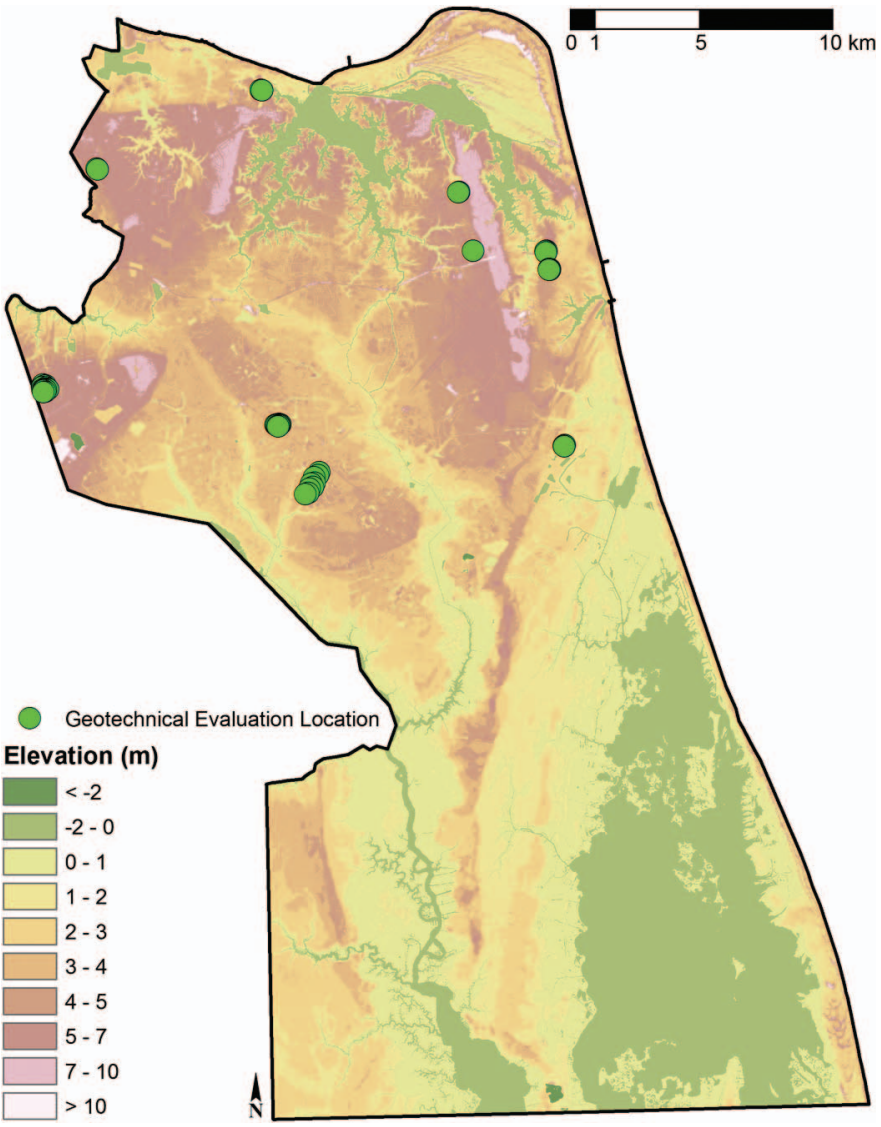

Fig. 14. (Color) Locations of the geotechnical evaluation points used for validating the SHWT depth grid. There are 57 points at 10 different sites, all in the northern half of the city.

Table 4. Summary statistics for the residuals of the validation points

\begin{tabular}{lcc}
\hline Statistic & Value & Unit \\
\hline$n$ & 57 & - \\
Minimum & -0.9 & $\mathrm{~m}$ \\
Maximum & 1.2 & $\mathrm{~m}$ \\
Minimum magnitude & 0.0 & $\mathrm{~m}$ \\
Maximum magnitude & 1.2 & $\mathrm{~m}$ \\
Mean & 2 & $\mathrm{~cm}$ \\
SSR & 12 & $\mathrm{~m}^{2}$ \\
RMSE & 0.5 & $\mathrm{~m}$ \\
\hline
\end{tabular}

on the result are unknown. In this study, the water table elevation beneath the land surface is the product of linear interpolation from one water surface to another. Such interpolation results in a linear gradient between water bodies that disregards soil properties and land surface elevations. In reality, the water table follows a subdued version of surface topography due to a combination of pressure forces and capillary action, limited by soil properties and other geologic features (Peck and Payne 2003). Fig. 16(a) demonstrates how this concept translates to the actual SHWT model. The SHWT elevation was estimated irrespective of the surrounding soil, geology, and land surface condition. The predicted SHWT elevation clearly lacks features of the surrounding topography, including the ridge. The SHWT elevation should rise with the ridge rather than exhibit a steady decline toward the estuary in the east. The grid estimate of the water table would remain unchanged if the land elevation between the water bodies were altered, as conceptualized
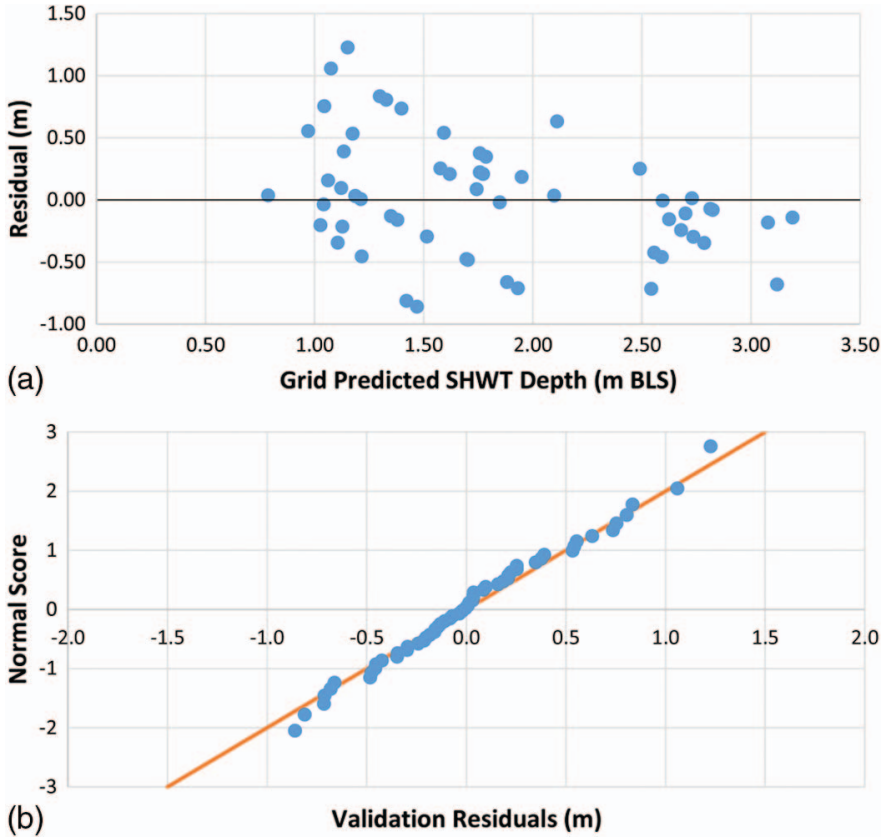

Fig. 15. (Color) (a) The residual plot in which the observed values are the geotechnical evaluation final recommendations and the predicted values are from the SHWT depth grid; and (b) the normal probability plot used to verify the distribution of validation residuals.

in Figs. 16(b and c). In effect, the accuracy was limited by the concentration of water bodies across the land surface. More water bodies result in more input points, which allow the predicted water table surface to follow the land surface more closely. Because there are no water bodies on the highest points of the ridge, the results along the ridge and similar areas likely overestimate the SHWT depth. A potential remedy for this would be to incorporate groundwater readings from ridges directly into creation of the TIN, being careful to choose readings from the same season as the DEM.

Streets and other artifacts from the DEM were very evident in the SHWT model. Minor streets are often $15 \mathrm{~cm}$ below the surrounding land. The height difference was readily reflected in the SHWT model because the streets were $15 \mathrm{~cm}$ closer to the water table than their adjacent areas. Streets and other land surface depressions did not, however, impact the SHWT elevation estimates. Streets or other artifacts may not be desired in the depth grid because they may skew results when, for example, finding the average water table depth in a drainage area. To correct for this, the DEM may be modified in some way to hide street footprints, then the SHWT elevation grid could be subtracted from the modified DEM and a new SHWT model would result that does not contain such artifacts.

Additional sources of error leading to the predicted street depression spring locations include the open water surfaces used as inputs for the initial November 2012 water table elevation estimate. Including a pond or other water body that was not reflected in the DEM would result in a much shallower prediction, including the prediction of a spring in street depressions and other areas where the DEM was lower than average. It was more likely that the water table under street depressions was high, but not so high that the groundwater threatened to well up from the surface periodically. Drainage intervention may also have dewatered groundwater flooding in these areas. Accounting for the underlying soil and geology could alter the SHWT depth estimate in those areas and provide a more accurate prediction. 

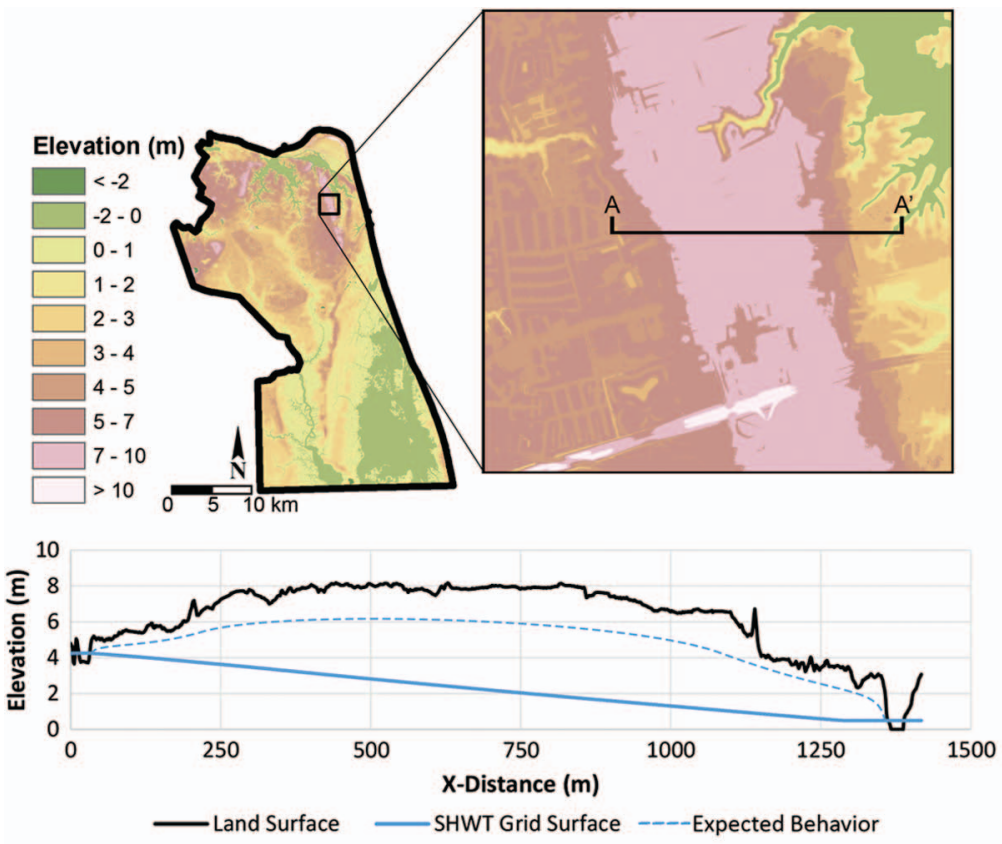

(a)

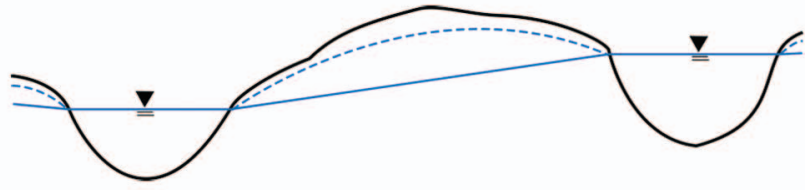

(b)

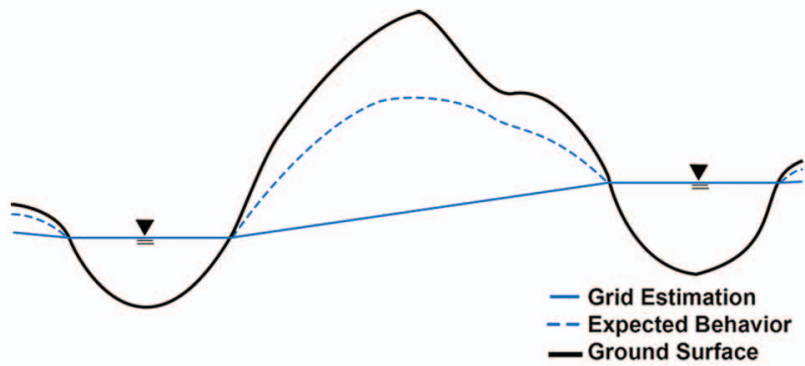

(c)

Fig. 16. (Color) (a) A comparison of the land surface elevation and the SHWT elevation at a portion of Oceana Ridge (shown as cross section A-A') in the city of Virginia Beach. The ridge is around $3.0 \mathrm{~m}$ higher than the surrounding land. The SHWT elevation does not reflect surface topography, as would be expected; (b) plot of the SHWT depth grid along cross section A-A' for original conditions; (c) plot of the SHWT depth grid along cross section A-A' for raised land conditions. A cross-sectional representation of how the SHWT depth grid ultimately represents the physical character of the water table; and (c) demonstration of how the predicted water table elevation does not respond as expected when the land surface elevation is increased from the original condition. The SHWT model predicts a water table deeper than expected, especially at locations far from water bodies, due to inability to account for land surface elevation and geologic conditions, including soils.

The methodology used to create the SHWT model ignores the underlying soil and geology in other ways. Although November 2012 was drier than usual, the soils underneath the lakes and ponds would affect the rate of dewatering; some ponds would therefore contain more stormwater than other ponds, elevating the water surface and effectively increasing the estimated SHWT elevation in those locations. In addition, the presence of perched water tables was neglected by this methodology, as are areas of highly localized anthropogenic impacts that are not reflected in adjacent water surfaces.

The method and parameters chosen to interpolate the AF grid have potential to significantly impact results. IDW interpolation was used because it directly incorporates the input points in the final surface, and the resulting IDW surface does not exceed the lowest or highest values from the input data set. Considering the use of the end product as part of a preliminary site planning tool, operating within the bounds of the known data was deemed an acceptable approach. Other, more rigorous geostatistical methods could be adapted to this application, assuming sufficient data are available and result bounds are acceptable.

The highest observed April median was used to calculate the $\mathrm{AF}$, rather than an average observed April median, in order to generate a surface that would ideally represent the highest potential SHWT at all points for conservative BMP siting. The highest observed April medians did not occur at the same point in time owing to spatial variability in soil conditions, precipitation, anthropogenic influences, and other complicating factors. The surfaces are not representative of a specific or average year condition and should not be used as such. Although the SHWT model was created using the highest observed April median, the final grid presents a moderate surface with accuracy of $\pm 0.9 \mathrm{~m}$ at a $95 \%$ confidence interval.
Lack of available long-term monitoring data may limit the full implementation of this methodology outside of the study area. However, if the Lidar data were obtained between January and April, interpolation of water surfaces without an adjustment factor would provide comparable results, suitable for preliminary BMP siting.

\section{Conclusion}

A method for estimating SHWT was developed using readily available soil and hydrography data sets, and was evaluated for accuracy by comparing them to long-term monitoring data. Surface water elevations were obtained from available GIS data sets and used as boundaries to estimate the SHWT. Surface water elevations were interpolated and the results adjusted to seasonal high values on the basis of the highest April median from long-term monitoring data. The resulting SHWT model was compared to the median April median from long-term monitoring data, available soil and hydrography data sets, and available water table measurements from construction soil bores. This method was shown to produce a more accurate estimate than available RMF-based SHWT data, and was found to be representative of SHWT estimates from soil bores. The methodology requires easily accessible spatial layers, is straightforward to implement, and could be used to more accurately predict the SHWT in other coastal locations with similar geological characteristics.

A representative surface for a specific or average year could be created by altering the $\mathrm{AF}$ - for example, by finding the difference between the November 2012 median and the mean April median, rather than the highest April median. Within the confines of the 
current methodology, the SHWT model could be improved by altering the input data. Because the predicted water table elevation is dependent on the presence of water surfaces, areas with more water surfaces are likely more accurate than areas with fewer water surfaces. Identifying missed ponds or reaches in areas relatively far from other water bodies and incorporating them into the input data could improve prediction accuracy. Wetland boundaries could provide valuable input data points, although the elevation of wetland boundaries would already represent the SHWT and would not need to be adjusted. Of course, there is much room for expansion of the methodology, such as obtaining more geotechnical evaluation data and directly incorporating that information into the SHWT model, utilizing soil properties and other thematic layers to modify the initial elevation estimate, or development and calibration of a hydrogeologic model, but all are beyond the scope of the limited informational resources available.

Despite the linear representation of the physical character of the water table, it was concluded that the SHWT model provided a more accurate estimate of the SHWT depth throughout the city than the available SSURGO data, which likely did not account for the substantial anthropogenic impacts on the water table in Virginia Beach. The SHWT model should be used with caution, however. The grid is not a substitute for direct measurement and is meant only for planning purposes. All predicted water table depths should be verified in situ.

\section{Acknowledgments}

The authors express their appreciation to Greg Johnson, Department of Public Works, City of Virginia Beach, Virginia; Kathleen Hancock, Department of Civil and Environmental Engineering, Virginia Tech; and Conrad Heatwole and Durelle Scott, Department of Biological Systems Engineering, Virginia Tech, who facilitated and helped guide this research, and provided constructive comment. Portions of this research were funded by the City of Virginia Beach, Project 449263; however, opinions expressed within are entirely of the authors and reflect no endorsement by the City. Any use of trade, firm, or product names is for descriptive purposes only and does not imply endorsement by the US Government. Funding for this research was also was provided in part by the Virginia Agricultural Experiment Station and the Hatch program of the National Institute of Food and Agriculture, US Department of Agriculture, which also does not imply endorsement of opinions contained herein.

\section{References}

Agarwal, R., and P. K. Garg. 2016. "Remote sensing and GIS based groundwater potential and recharge zones mapping using multi-criteria decision making technique." Water Resour. Manage. 30 (1): 243-260. https://doi.org/10.1007/s11269-015-1159-8.

Battiata, J., K. Collins, D. Hirschman, and G. Hoffmann. 2010. "The runoff reduction method." J. Contemp. Water Res. Educ. 146 (1): 11-21. https://doi.org/10.1111/j.1936-704X.2010.00388.

Brown, R. A., and W. F. Hunt. 2011. "Impacts of media depth on effluent water quality and hydrologic performance of undersized bioretention cells." J. Irrig. Drain. Eng. 137 (3): 132-143. https://doi.org/10 .1061/(ASCE)IR.1943-4774.0000167.

Brown, R. A., and W. F. Hunt. 2012. "Improving bioretention/biofiltration performance with restorative maintenance." Water Sci. Technol. 65 (2): 361-367. https://doi.org/10.2166/wst.2012.860.

City of Virginia Beach. 2016. "Open GIS data." Accessed January 11, 2016. http://gis.data.vbgov.com/.
Daniels, R. B., E. E. Gamble, and L. A. Nelson. 1971. "Relations between soil morphology and water-table levels on a dissected North Carolina coastal plain surface." Soil Sci. Soc. Am. J. 35 (5): 781-784. https://doi .org/10.2136/sssaj1971.03615995003500050041x.

D.C. Water Resources Research Center. 1995. Development of a groundwater contour map for the water table aquifer in the Atlantic coastal plain deposits of Washington, DC. Washington, DC: Univ. of the District of Columbia.

Eggleston, J. R. 2010. Outdoor water use and water conservation opportunities in Virginia Beach. Fact Sheet 2010-3007. Richmond, VA: US Geological Survey.

Esri. 2016. "ArcGIS for desktop." Accessed January 12, 2015. http:// desktop.arcgis.com/en/arcmap/.

Humphrey, C. P. J., and M. A. O’Driscoll. 2011. "Evaluation of soil colors as indicators of the seasonal high water table in coastal North Carolina." Int. J. Soil Sci. 6 (2): 103. https://doi.org/10.3923/ijss.2011.103.113.

James, H. R., and T. E. Fenton. 1993. "Water tables in paired artificially drained and undrained soil catenas in Iowa." Soil Sci. Soc. Am. J. 57 (3): 774-781. https://doi.org/10.2136/sssaj1993.03615995005700030025x.

Johnson, R. D., and D. J. Sample. 2017. "A semi-distributed model for locating stormwater best management practices in coastal environments." Environ. Modell. Software 91 (May): 70-86. https://doi.org/10 .1016/j.envsoft.2017.01.015.

Kumar, T., A. K. Gautam, and T. Kumar. 2014. "Appraising the accuracy of GIS-based multi-criteria decision making technique for delineation of groundwater potential zones." Water Resour. Manage. 28 (13): 4449-4466. https://doi.org/10.1007/s11269-014-0663-6.

Li, F., W. Wei, Y. Zhao, and J. Qiao. 2017. "Groundwater depth prediction in a shallow aquifer in north China by a quantile regression model." Hydrogeol. J. 25 (1): 191-202. https://doi.org/10.1007/s10040-016-1473-0.

Machiwal, D., M. K. Jha, and B. C. Mal. 2011. "Assessment of groundwater potential in a semi-arid region of India using remote sensing, GIS and MCDM techniques." Water Resour. Manage. 25 (5): 1359-1386. https://doi.org/10.1007/s11269-010-9749-y.

Madani, A., and B. Niyazi. 2015. "Groundwater potential mapping using remote sensing techniques and weights of evidence GIS model: A case study from Wadi Yalamlam basin, Makkah province, western Saudi Arabia." Environ. Earth Sci. 74 (6): 5129-5142. https://doi.org/10 .1007/s12665-015-4524-2.

McKenzie, A. A., H. K. Rutter, and A. G. Hulbert. 2010. "The use of elevation models to predict areas at risk of groundwater flooding." Geol. Soc. London Spec. Publ. 345 (1): 75-79. https://doi.org/10.1144/SP345.9.

Morgan, C. P., and M. H. Stolt. 2006. "Soil morphology-water table cumulative duration relationships in southern New England." Soil Sci. Soc. Am. J. 70 (3): 816-824. https://doi.org/10.2136/sssaj2004.0071.

Northeast Regional Climate Center. 2015. "Northeast RCC CLIMOD II." Accessed March 2, 2015. http://climodtest.nrcc.cornell.edu/.

Oaks, R. Q., and N. K. Coch. 1973. Post-Miocene stratigraphy and morphology, southeastern Virginia, 135. Charlottesville, VA: Commonwealth of Virginia, Division of Mineral Resources.

Patil, S. G., and N. M. Mohite. 2014. "Identification of groundwater recharge potential zones for a watershed using remote sensing and GIS.” Int. J. Geomatics Geosci. 4 (3): 485-498.

Peck, M. F., and D. F. Payne. 2003. "Development of an estimated watertable map for coastal Georgia and adjacent parts of Florida and South Carolina." In Proc., Georgia Water Resources Conf., edited by K. J. Hatcher. Athens, Georgia: Univ. of Georgia.

Sahoo, S., M. K. Jha, N. Kumar, and V. M. Chowdary. 2015. "Evaluation of GIS-based multicriteria decision analysis and probabilistic modeling for exploring groundwater prospects." Environ. Earth Sci. 74 (3): 2223-2246. https://doi.org/10.1007/s12665-015-4213-1.

Sander, P., M. M. Chesley, and T. B. Minor. 1996. "Groundwater assessment using remote sensing and GIS in a rural groundwater project in Ghana: Lessons learned." Hydrogeol. J. 4 (3): 40-49. https://doi.org/10 $1007 / \mathrm{s} 100400050086$

Sanford, W. E., D. L. Nelms, J. P. Pope, and D. L. Selnick. 2015. "Estimating mean long-term hydrologic budget components for watersheds and counties: An application to the commonwealth of Virginia, USA." Hydrol. Curr. Res. 6: 191. https://doi.org/10.4172/2157-7587.1000191. 
Smith, B. S. 2003. Ground-water flow and saline water in the shallow aquifer system of the southern watersheds of Virginia Beach, Virginia. Water-Resources Investigations Rep. 03-4258. Richmond, VA: US Dept. of the Interior and US Geological Survey.

Smith, B. S. 2005. Simulated changes in water levels caused by potential changes in pumping from shallow aquifers of Virginia Beach, Virginia. Scientific Investigations Rep. 05-5067. Richmond, VA: US Dept. of the Interior and US Geological Survey.

Smith, B. S., and G. E. Harlow. 2002. Conceptual hydrogeologic framework of the shallow aquifer system at Virginia Beach, Virginia. WaterResources Investigations 01-4262. Richmond, VA: US Dept. of the Interior and US Geological Survey.

Susilo, K., N. Matasovic, and R. S. Johnson. 2009. "Considerations, opportunities, and strategies for infiltration stormwater BMPs." In World Environmental and Water Resources Congress 2009: Great Rivers, 971-980. Reston, VA: ASCE.

Thompson, J. A., S. Roecker, S. Grunwald, and P. R. Owens. 2012. "Digital soil mapping: Interactions with and applications for hydropedology." In Hydropedology: Synergistic integration of soil science and hydrology, edited by H. Lin, 665-709. Cambridge, MA: Academic Press.
USDA NRCS. 2015. "Technical soil services handbook." Accessed December 7, 2015. http://www.nrcs.usda.gov/wps/portal/nrcs/detail /soils/ref/?cid=nrcs142p2_053385.

Vepraskas, M. J., and L. P. Wilding. 1983. "Aquic moisture regimes in soils with and without low chroma colors." Soil Sci. Soc. Am. J. 47 (2): 280-285. https://doi.org/10.2136/sssaj1983.03615995004700020022x.

Vijay, R., A. Sharma, S. S. Ramya, and A. Gupta. 2011. "Fluctuation of groundwater in an urban coastal city of India: A GIS-based approach." Hydrol. Processes 25 (9): 1479-1485. https://doi.org/10.1002/hyp.7914.

Virginia Beach City GIS. 2014. Hydrography surfaces. Virginia Beach, VA: Virginia Beach GIS Department.

Virginia Beach Department of Public Works Operations Management. 2016. FLOOD service request log. Virginia Beach, VA: Virginia Beach Utilities Department .

Virginia Department of Environmental Quality. 2011. Virginia DEQ stormwater design specification No. 9, Bioretention, Version 1.9, March 1, 2011. Richmond, VA: Virginia Dept. of Environmental Quality.

Virginia Department of Environmental Quality. 2013a. BMP standards nd specifications. Richmond, VA: Virginia Dept. of Environmental Quality.

Virginia Department of Environmental Quality. 2013b. Virginia stormwater management handbook, 5-17. Richmond, VA: Virginia Dept. of Environmental Quality. 